\title{
Aa. Vv., Fiction et cultures, sous la direction de Françoise Lavocat et Anne Duprat
}

\section{Orlando Bonserio}

\section{OpenEdition}

\section{Journals}

\section{Edizione digitale}

URL: http://journals.openedition.org/studifrancesi/5818

DOI: $10.4000 /$ studifrancesi.5818

ISSN: 2421-5856

\section{Editore}

Rosenberg \& Sellier

\section{Edizione cartacea}

Data di pubblicazione: 1 septembre 2011

Paginazione: 478-479

ISSN: 0039-2944

\section{Notizia bibliografica digitale}

Orlando Bonserio, «Aa. vv., Fiction et cultures, sous la direction de Françoise Lavocat et Anne Duprat», Studi Francesi [Online], 164 (LV | II) | 2011, online dal 30 novembre 2015, consultato il 10 janvier 2021. URL: http://journals.openedition.org/studifrancesi/5818; DOI: https://doi.org/10.4000/studifrancesi. 5818

Questo documento è stato generato automaticamente il 10 janvier 2021.

\section{(c) (i) (9)}

Studi Francesi è distribuita con Licenza Creative Commons Attribuzione - Non commerciale - Non opere derivate 4.0 Internazionale. 


\title{
Aa. Vv., Fiction et cultures, sous la direction de Françoise Lavocat et Anne Duprat
}

\author{
Orlando Bonserio
}

\section{NOTIZIA}

Aa. VV., Fiction et cultures, sous la direction de Françoise LAVOCAT et Anne DUPRAT, Société Française de Littérature Générale et Comparée, Paris, 2010, 320 pp.

1 Che cos'è la "fiction"? Quale definizione le si può dare? Quale funzione può avere, quale significato, quale rapporto con la filosofia, la psicologia, l'antropologia, la sociologia, con la letteratura stessa? Questo volume ci aiuta ad approfondire e a trovare delle risposte a queste domande, ma anche a far sorgere delle nuove questioni, a dissipare o instillare nuovi dubbi o, per meglio dire, nuovi punti di vista. Infatti, la prospettiva adottata è quella comparatistica, essendo questo testo edito dalla Société Française de Littérature Générale et Comparée, e vengono raccolti i contributi di studiosi ed esperti di quasi ogni parte del mondo, che ci propongono diverse visioni del concetto di "fiction", al punto che forse sarebbe più corretto parlare di fictions al plurale. Come dice Jean-Marie SCHAEFFER («sûrement celui dont les travaux ont le plus ouvert la voie comparatiste», dice una delle curatrici a p. 14) nella sua «Préface» (pp. 7-9), «le présent ouvrage [...] apporte une contribution importante à une meilleure compréhension de la fiction, sous sa double face de fait littéraire culturellement situé et de fait transculturel (puisque l'approche comparative n'a de sens que si les objets comparés ont des points en commun)». La sua concezione della fiction prevede, oltre alla (labile) separazione tra verità e menzogna, anche un aspetto ludico; a titolo esemplificativo, basta puntare lo sguardo sull'evoluzione della letteratura francese (analizzata, insieme al resto della letteratura europea e nordamericana moderna, nel capitolo Du métatextuel au métafictionnel: états de la fiction occidentale aux XIX et XX siècles, ad opera di Richard SAINT- 
GELAIS, Jean-Louis JEANNELLE e Karen HADDAD-WOTLING, pp. 266-280): i primi due aspetti (e soprattutto la loro confusione) sono rintracciabili nel concetto di autofiction, mentre il gioco rientra fra le componenti di avanguardie come l'Oulipo o il Nouveau Roman.

Françoise LAVOCAT, una delle curatrici dell'opera, evidenzia nell' «Introduction» (pp. 11-31) le problematiche di una definizione teorica e la confusione che regna intorno a questa categoria, e chiarisce come la fiction non sia un genere a sé ma un insieme di pratiche spesso e volentieri confuso con il romanzo, in quanto più connesso all'aspetto estetico che a una adesione alla realtà o verità referenziali (e quindi, a sua volta, opposto al realismo). Questo intervento introduttivo è anche volto a sottolineare difficoltà, concezioni e usi della finzione, e stabilisce che «l'objet de ce livre n'est donc pas de proposer une nouvelle définition de la fictionnalité. Il s'agirait plutôt de suspendre, peut-être provisoirement, celles qui nous sont devenues trop familières [...] au profit d'une description des usages de la fiction, dans une optique comparative, aussi large que possible» (p.14).

In effetti, l'ottica comparatistica è decisamente vasta, perché non solo vengono prese in esame svariate aree culturali, ma spesso di tali aree vengono considerate anche diverse epoche. Ad esempio, nella sezione riguardante il mondo arabo sono presenti i capitoli La notion de quasi acte et la naissance de la fiction dans la poésie arabe médiévale (di Hachem FODA, pp. 73-92) e Peur de la fiction? Le cas de la culture arabe moderne (di Maya BOUTAGHOU, pp. 93-110); in quella sulla Cina Comment la fiction vint aux Chinois (di Philippe POSTEL, pp. 127-148) e La fiction retrouvée: questions sur la genèse de la littérature chinoise moderne (di Sebastian VEG, pp. 149-164); sul Giappone La fiction dans la littérature du Japon classique (di Daniel STRUVE, pp. 165-175) e Procès de la fiction, procès de la littérature: sur quelques cas au Japon, che esula un po' dal discorso critico-letterario per analizzare gli effetti della finzione sul reale, in questo caso gli effetti legali (di Yasusuke ouRA, pp. 176-186). L'approccio diacronico più ampio resta tuttavia quello dedicato all'area occidentale (Europa e Stati Uniti), che può contare tre interventi: oltre a quello già citato, sono presenti anche i saggi di Anne DUPRAT e Teresa CHEVROLET (La bataille des fables: conditions de l'émergence d'une théorie de la fiction en Europe (XIV-XVII siècle), pp. 239-254) e quello di Jan HERMAN (Approches systémiques de la fiction aux XVII et XVIII siècles, pp. 255-265). Le altre aree culturali abbracciate da questo volume sono quella del mondo greco antico ( $\mathrm{La}$ pragmatique poétique des mythes grecs: fiction référentielle et performance rituelle di claude CALAME, pp. 33-56); del mondo ebraico medievale (Réalité et fiction dans la littérature hébraïque au moyen âge: l'exégèse biblique et le récit de voyage comme cas d'étude di Revital REFAEL-VIVANTE, pp. 57-72); dell'Africa (Usages de la fiction en Afrique, di Xavier GARNIER e Jean DERIVE, pp.111-126); dell'India (Le mensonge de Yudhisthira, ou la fiction de l'Inde, di Rukmini BHAYA NAIR, pp.187-200, e Fictionnalité et factualité dans l'Inde moderne et contemporaine, di Didier cosTE, pp. 201-212); dell'America Latina e Caraibi (États de fiction, fictions d'États, di Annick LouIs, pp.213-227, e Fiction dans les Carailbes: de la mémoire culturelle à la globalisation, di Anja BANDAU e Christoph SINGLER, pp. 228-238).

Un altro aspetto interessante di questa raccolta è che il concetto di area culturale non è solamente inteso come cultura storicamente e geograficamente delimitata, bensì come diverso tipo, o supporto, di cultura: è il caso, ad esempio, della finzione nei film o nei giochi di ruolo che viene analizzata da Olivier CAÏRA in Fiction et industries de divertissement (pp. 281-292). 
5 Emerge da questo libro che il concetto di fiction è, come forse quello di letteratura, un concetto vasto ma astratto e forse abusato, vario, molteplice e multiplo, e perciò continuamente discusso e studiato: l'ultimo capitolo, Fiction et cultures vs fictions et culture: éléments de bibliographie di Anne DUPRAT e Françoise Lavocat (pp. 293-312) ci dà dei punti di riferimento bibliografici per poterci orientare nel dibattito su questo argomento. 